\title{
Robust Short-Latency Perisomatic Inhibition onto Neocortical Pyramidal Cells Detected by Laser-Scanning Photostimulation
}

\author{
Julia Brill and John R. Huguenard \\ Department of Neurology and Neurological Sciences, Stanford University School of Medicine, Stanford, California 94305
}

Inhibitory connectivity onto neocortical pyramidal cells was mapped using LSPS (laser-scanning photostimulation/glutamate uncaging). The average onset latency of IPSCs was shorter than that of EPSCs recorded in the same cells, indicating a specific mechanism for rapid network recruitment of inhibition. The majority of strong inhibitory synaptic inputs originated within $300 \mu \mathrm{m}$ of the recorded cell's

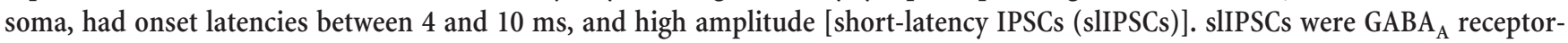
mediated chloride currents that were evoked in an all-or-none manner. We tested whether slIPSCs resulted from somatic depolarization of presynaptic interneurons or from direct excitation of inhibitory presynaptic terminals via kainate receptors. Our evidence supports the former hypothesis: (1) sIIPSCs had similar sensitivity to kainate and AMPA receptor blockers as electrically evoked EPSCs. (2) slIPSCs frequently had an notched rising phase suggestive of summated IPSCs resulting from repetitive firing of presynaptic neurons. (3) Latencies and interevent intervals were consistent with spike latencies and interspike intervals in fast-spiking (FS) interneurons. (4) sIIPSCs were frequently evoked at spots where the recorded cell was also excited directly, but $\sim 15 \%$ of spots from which slIPSCs were evoked did not overlap with the recorded neuron's cell body. We propose that slIPSCs from FS interneurons represent a pool of powerful inhibitory signals that can be recruited by local excitation. Because of their magnitude, progressive recruitment, and short latency, sIIPSCs are a effective mechanism of regulating excitability in neocortical circuits.

\section{Introduction}

Neocortical GABAergic interneurons shape network activity and information processing by providing feedforward and feedback inhibition onto principal neurons and onto themselves. They comprise a range of subtypes that can be discriminated on the basis of their morphology, electrophysiological properties, and marker protein expression (Markram et al., 2004; Bacci et al., 2005; Yuste, 2005; Wonders and Anderson, 2006). Arguably, the most profound distinction is drawn between fast-spiking (FS) and non-FS interneurons. FS interneurons, i.e., basket and chandelier cells, have high maximal firing rates $(>200 \mathrm{~Hz})$, synapse onto the soma and proximal dendrites (basket cells) (MarinPadilla, 1972) or axon initial segments (chandelier cells) (Somogyi, 1977) of pyramidal neurons, and express the calciumbinding protein parvalbumin. The perisomatic or axonal inhibition exerted puts them in a position to exercise powerful control over pyramidal cell output and synchronization (Freund and Katona, 2007). Interneurons and pyramidal neurons receive both excitatory and inhibitory input. Whereas pyramidal cells are believed to be targeted by virtually all interneuron types and vice

\footnotetext{
Received Dec. 22, 2008; revised April 14, 2009; accepted April 30, 2009.

This work was supported by National Institute of Neurological Disorders and Stroke Grant NS12151 (J.R.H.) and an American Epilepsy Society postdoctoral fellowship (J.B.).

Correspondence should be addressed to John R. Huguenard, Department of Neurology and Neurological Sciences, Stanford University School of Medicine, 300 Pasteur Drive, Room M016, Stanford, CA 94305. E-mail: john.huguenard@stanford.edu.

DOI:10.1523/JNEUROSCI.6098-08.2009

Copyright $\odot 2009$ Society for Neuroscience $\quad$ 0270-6474/09/297413-11\$15.00/0
}

versa, interneurons preferentially target other interneurons of the same types through electrical and to a lesser extent chemical synapses (Gibson et al., 1999; Beierlein et al., 2000; Galarreta and Hestrin, 2002; Bacci et al., 2005).

Laser-scanning photostimulation/glutamate uncaging (LSPS) is a powerful technique to investigate connectivity of different types of neurons. Release of glutamate onto neuronal somata can cause suprathreshold depolarization (via direct activation of somatic glutamate receptors) and action potential generation, such that the location and laminar origin of presynaptic neurons can be determined. Studies using LSPS have revealed that excitatory and inhibitory neocortical connections display great laminar target sensitivity. For example, Dantzker and Callaway (2000) have shown that in rat somatosensory cortex, pyramidal cells and FS interneurons in layer $2 / 3$ receive excitatory input mainly from layer $4 / 5 \mathrm{a}$, whereas other interneuronal classes received the majority of inputs from layer $5 \mathrm{~b}$ or 2 . Different types of interneurons in layer $2 / 3$ of mouse somatosensory cortex display strikingly different excitatory and inhibitory input maps ( $\mathrm{Xu}$ and Callaway, 2009). In rat barrel cortex, layer 4 sends excitatory projections to layer 2/3 barrel cells, whereas layer 5a projects to cells in the septa between barrels (Shepherd and Svoboda, 2005). Layer 4 stellate cells receive excitatory input from within layer 4 in the same barrel, whereas layer 4 pyramidal cells receive significant excitatory inputs from infragranular layers. However, both cell types receive mainly intralaminar inhibitory inputs (Schubert et al., 2003).

In this study, we examine inhibitory connectivity in rat so- 
matosensory cortex. We found that distinct patterns of connectivity can be distinguished when IPSCs are sorted according to their onset latency. We present several lines of evidence showing that under our experimental conditions, short-latency $(<10 \mathrm{~ms})$ IPSCs predominantly represent input from FS interneurons, and that ISPC latencies of as little as $3.2 \mathrm{~ms}$ are consistent with somatic depolarization and action potential generation in the presynaptic interneuron. Thus, short-latency IPSPs mediated by FS interneurons represent a powerful and rapidly recruited means of regulating neocortical excitability.

\section{Materials and Methods}

Slice preparation. All experiments were performed according to protocols approved by the Stanford Institutional Animal Care and Use Committee. Sprague Dawley rats aged postnatal day (P) 16 to P20 were deeply anesthetized using $50 \mathrm{mg} / \mathrm{kg}$ sodium pentobarbital, and brains were removed and immediately transferred to ice-cold sucrose solution containing (in mM) 234 sucrose, 11 glucose, $24 \mathrm{NaHCO}_{3}, 2.5 \mathrm{KCl}, 1.25 \mathrm{NaH}_{2} \mathrm{PO}_{4}, 2$ $\mathrm{MgSO}_{4}$, and $0.5 \mathrm{CaCl}_{2}$, equilibrated with a $95-5 \%$ mixture of $\mathrm{O}_{2}$ and $\mathrm{CO}_{2}$. Coronal neocortical slices $(350-400 \mu \mathrm{m})$ were sectioned on a VT $1000 \mathrm{~S}$ Vibratome (Leica) at $4^{\circ} \mathrm{C}$ in sucrose solution and transferred into a holding chamber filled with artificial CSF [ACSF (in mM): $126 \mathrm{NaCl}, 26$ $\mathrm{NaHCO}_{3}, 2.5 \mathrm{KCl}, 1.25 \mathrm{NaH}_{3} \mathrm{PO}_{4}, 2 \mathrm{CaCl}_{2}, 2 \mathrm{MgCl}_{2}, 10$ glucose, equilibrated with $\left.95 \% \mathrm{O}_{2} / 5 \% \mathrm{CO}_{2}, \mathrm{pH} 7.4\right]$. After a recovery period of $1 \mathrm{~h}$ at $32^{\circ} \mathrm{C}$, the holding chamber containing the slices was removed from the water bath and allowed to cool to room temperature.

Focal photolysis of caged glutamate/laser-scanning photostimulation. Focal photolysis of caged glutamate was performed as described previously (Deleuze and Huguenard, 2006; Jin et al., 2006; Kumar et al., 2007). A pulsed $355 \mathrm{~nm}$ UV laser beam (DPSS Lasers) was directed into the back aperture of the 5 or $63 \times$ microscope objective and was controlled with mirror galvanometers (Model 6210; Cambridge Technology) using a locally developed software program. Focal photolysis of 4-methoxy-7nitroindolinyl (MNI)-caged glutamate (Tocris; $100 \mu \mathrm{M}$ ) was triggered by $10-50 \mathrm{~mW}$ UV light pulses $(300-800 \mu \mathrm{s})$. MNI-caged glutamate was supplied in a $30 \mathrm{ml}$ recirculating bath solution. Typically, the bath solution was exchanged after 3-4h, or sooner if significant rundown of direct responses was detected (see below). Determination of uncaging beam half width was determined by scanning the beam in $1 \mu \mathrm{m}$ steps through the objective and measuring power via a UV sensitive light meter (Newport Power Meter Model 1815-C with Model 818-UV probe), which was obscured by a straight-edged razor blade placed at right angles to the scanning path. As the beam was stepped so that it became less progressively obscured by the blade, the light meter recorded increasing powers reflecting the integrated power of the entire beam. This cumulative power versus beam position curve was then differentiated to obtain a Gaussian curve from which the half width was determined.

Electrophysiological recordings. Slices were transferred to a recording chamber and constantly superfused with oxygenated ACSF at a rate of $\sim 2 \mathrm{ml} / \mathrm{min}$. Experiments were conducted at room temperature $\left(23-25^{\circ} \mathrm{C}\right)$, all cells recorded were located in primary somatosensory cortex in limb and trunk areas. Cortical layers were identified visually from an overview image at $5 \times$ magnification, and neurons were visualized at $63 \times$ magnification using differential contrast optics with an Axioskop 2 FS microscope (Zeiss). Pyramidal cells were identified based on their larger size, tear-shaped morphology, and thick apical dendrite. Cells were routinely filled with $0.3 \% \mathrm{w} / \mathrm{v}$ biocytin for postrecording recovery to confirm their identity. Whole-cell recordings were obtained using borosilicate glass electrodes with a tip resistance of 2-4 $\mathrm{M} \Omega$. The pipette solution used for connectivity mapping contained (in mM) 130 Csgluconate, $8 \mathrm{CsCl}, 10$ HEPES, 4 EGTA, and 0.01 QX314 [N-(2,6dimethylphenylcarbamoylmethyl) triethylammonium bromide], $\mathrm{pH} 7.3$ adjusted with $\mathrm{CsOH}$ (290 mOsm). For all current-clamp recordings, the following internal solution was used (in $\mathrm{mM}$ ): $120 \mathrm{~K}$-gluconate, $11 \mathrm{KCl}, 1$ $\mathrm{MgCl}_{2}, 1 \mathrm{CaCl}_{2}, 10 \mathrm{HEPES}, 10$ EGTA, pH 7.3 adjusted with $\mathrm{KOH}$. NMDA receptor-mediated currents were blocked by $50 \mu \mathrm{M}$ D-AP5 (Ascent Scientific). Either pipette solution was used for cell-attached recordings. Only recordings in which the series resistance was $<25 \mathrm{M} \Omega$ and changed $<30 \%$ during the recording were included in the data analysis, and no series resistance compensation was used. Membrane potentials were corrected for a liquid junction potential of $20 \mathrm{mV}$, and all voltages given subsequently include liquid junction potential correction. Signals were amplified with a Multiclamp 700A amplifier, sampled at $10 \mathrm{kHz}$ (whole-cell recordings), filtered at $3 \mathrm{kHz}$, acquired using a Digidata 1320A digitizer, and analyzed using pClamp9 (all Molecular Devices). Cell-attached recordings were sampled at $50 \mathrm{kHz}$. Action potential waveforms resemble the inverted first derivative of the membrane potential, starting with a negative deflection and ending with a positive deflection. Action potential onset was determined to be the visually identified onset of the negative deflection, and the end was defined as $90 \%$ decay time of the positive deflection (after the later "bump" for non-FS interneurons). Kainate and AMPA receptor blockers (UBP301 and GYKI-52466, both Tocris, $50 \mu \mathrm{M}$ each; and UBP302, Tocris, $30 \mu \mathrm{M}$ ) were applied in the bath solution. EPSCs were evoked by electrical stimulation using a concentric bipolar electrode (CB-XRC75, Frederick-Haer), and short-latency IPSCs (slIPSCs) were evoked by repeated glutamate uncaging at a given location. Events were evoked every 20-30 s. We typically recorded evoked PSCs during a 5-10 min control period, applied the blocker for $5 \mathrm{~min}$, and then washed for 10-15 min. For quantification of PSC amplitudes, the last $6-10$ events from each period were used. To account for potential time-dependent rundown of responses, "control" amplitudes for statistical analyses were calculated by averaging amplitudes measured during the initial control period and the end of the wash period. All recordings were performed in the presence of $50 \mu \mathrm{M}$ D-APV (Ascent Scientific).

Synaptic input maps. Maps consisted of 143-182 points spanning all cortical layers with a grid spacing of $90-100 \mu \mathrm{m}$. Points were stimulated in a pseudo-random pattern, designed to minimize sequential activation of adjacent grid points, with $5 \mathrm{~s}$ between stimuli. Typically, two maps were recorded at a holding potential of $-65 \mathrm{mV}$ to isolate EPSC input, where GABAergic activation results in small outward currents which do not interfere with the detection of the much larger inward glutamatergic currents. Subsequently, two maps were recorded at $-5 \mathrm{mV}$, close to the cation equilibrium potential, to isolate IPSCs. At $-5 \mathrm{mV}$, glutamatergic activation results in small inward currents which can be readily distinguished from outward GABAergic currents. In this way, direct excitation and synaptic inhibition could be simultaneously monitored in the same map. Direct glutamatergic currents are recorded when glutamate is released onto the cell body. These responses consistently have an onset latency of $<3 \mathrm{~ms}$ and were distinguished from EPSCs on that basis. We excluded sweeps in which direct activation exceeded $100 \mathrm{pA}$, such that it would interfere with detection of synaptic responses. To construct maps, we determined the cumulative amplitude of PSCs with onset latencies of 5-50 ms (EPSCs) and 2-50 ms (IPSCs) after the stimulus for each sweep. The cumulative amplitude is the sum of the amplitudes of all EPSCs recorded within the detection time window, and therefore represents a compound measure of event frequency and amplitude. We used a relatively short time window to avoid confounding effects of polysynaptic activation, whose contribution to overall synaptic responses were additionally minimized by blockade of NMDA receptors. PSCs were detected using locally written software, and validated by visual examination of raw traces. We then corrected the cumulative amplitude for the expected spontaneous activity in the equivalent time window. When two maps using the same grid were recorded, they were averaged.

Statistics. Data are given as average \pm SEM. Statistical comparisons between two groups were calculated using Student's $t$ tests, with $p$ values $<0.05$ indicating significance. Paired $t$ tests were used to analyze the results shown in Figures $2 D, 3 E$, and $5 C$; other comparisons were done using unpaired $t$ tests. Comparisons between three groups were done using ANOVA followed by Tukey's honestly significant difference post test.

\section{Results}

Inhibitory inputs to pyramidal cells are dominated by shortlatency high-amplitude events

We used LSPS to map inhibitory inputs onto layer $2 / 3$ and layer 5 pyramidal cells in primary somatosensory cortex of rats aged P16-P20. Focal photolysis of caged glutamate onto neuronal so- 

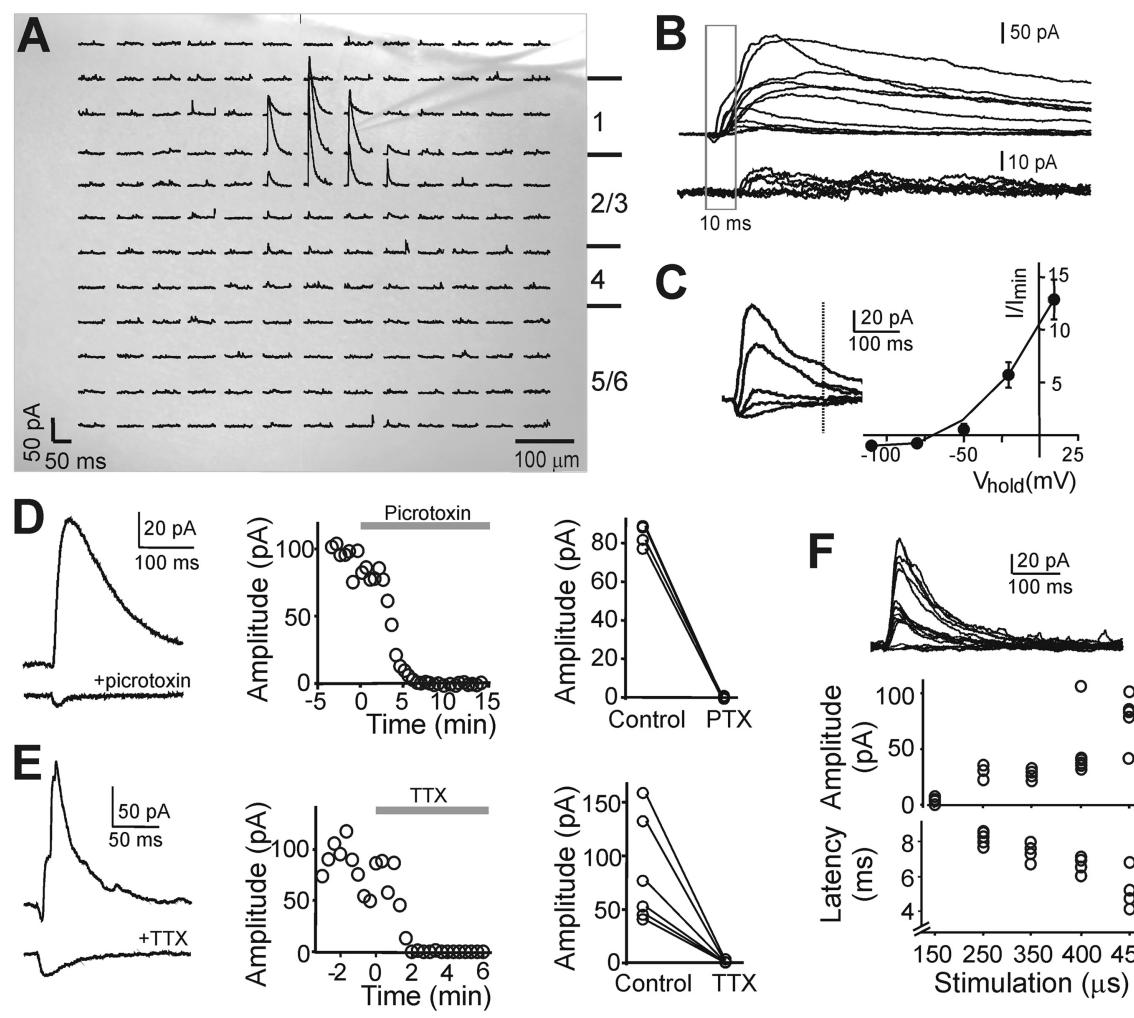

latencies of $<10 \mathrm{~ms}$ (top) and $>10 \mathrm{~ms}$ (bottom). The majority of large events had an onset latency of $<10 \mathrm{~ms}$.

\section{Short-latency events are $\mathrm{GABA}_{\mathrm{A}}$ receptor-mediated synaptic events}

We characterized these short-latency, high-amplitude events by repeatedly stimulating a location from which they could be evoked. Current/voltage curves were recorded $(n=5)$, showing that they were outwardly rectifying and had a reversal potential between -65 and $-70 \mathrm{mV}$, which is around the calculated chloride reversal potential of $-68 \mathrm{mV}$ (Fig. 1C). They were blocked by the $\mathrm{GABA}_{\mathrm{A}}$ receptor antagonist picrotoxin $(50 \mu \mathrm{M} ; n=4)$, whereas the glutamatergic direct currents evoked concomitantly (since the stimulation sites were close to the recorded cells' soma) were unaffected (Fig. 1D). Short-latency events were also completely blocked by 1 $\mu \mathrm{M}$ TTX, a blocker of voltage-gated sodium channels, showing that they were action potential dependent $(n=6)$, whereas the direct glutamatergic inward current was again unaffected (Fig. $1 E$ ). Changing the stimulation intensity by varying the laser pulse duration revealed stepwise increases in event amplitude and all-or-none responses (for an example, see Fig. $1 F$, top panel; similar response patterns were seen in 6 out of 6 cells), which are characteristic of synaptically mediated currents. We conclude that the short-latency events are synaptic $\mathrm{GABA}_{\mathrm{A}}$ receptor-mediated IPSCs (slIPSCs). Event latency decreased with increasing stimulus intensity in all cells analyzed (for an example, see Fig. $1 F$, bottom panel), which may reflect the fact that presynaptic cells reach spike threshold faster during stronger glutamatergic activation.

\section{sIIPSCs provide the majority of inputs to pyramidal cells and FS interneurons but not non-FS interneurons}

LSPS studies commonly quantify only events with an onset latency of $>10 \mathrm{~ms}$, and it has been suggested that monosynap-

mata, but not other subcellular compartments, can cause suprathreshold depolarization which elicits synaptic responses in postsynaptic cells. We recorded pyramidal cells in voltage-clamp mode at $-5 \mathrm{mV}$, which is near the cation reversal potential of 0 $\mathrm{mV}$. The chloride reversal potential in our experiments was -68 $\mathrm{mV}$, so that we were able to record IPSCs as large, outward currents. EPSCs and direct activation by LSPS directly onto the recorded cell evoked small inward currents which did not interfere with detection of IPSCs. This enabled us to directly examine inhibitory $\mathrm{GABA}_{\mathrm{A}}$ receptor-mediated synaptic inputs. Figure $1 \mathrm{~A}$ shows recordings from a representative layer $2 / 3$ pyramidal cell. Stimulation in close proximity to the recorded cell's soma resulted in large $(>100 \mathrm{pA})$ outward currents. Figure $1 B$ shows representative traces from that cell showing events with onset tic responses are unlikely to have shorter latencies because of the combined delays of time to reach spike threshold in the presynaptic neuron and subsequent synaptic delay (Dantzker and Callaway, 2000; Jin et al., 2006; Xu and Callaway, 2009). We therefore constructed inhibitory input maps for layer $2 / 3(n=8)$ and layer $5(n=7)$ pyramidal cells and separated inputs into those with an onset latency of $2-10 \mathrm{~ms}$ and $10-50 \mathrm{~ms}$ (Fig. 2A1,A2). The maps depict cumulative inputs, i.e., the sum of the amplitudes of all detected outward events (see Materials and Methods). The inputs to pyramidal cells in both layers with the highest cumulative amplitudes indeed had onset latencies of $<10 \mathrm{~ms}$ and originated perisomatically. Although IPSCs with onset latencies of $>10 \mathrm{~ms}$ had significantly smaller cumulative amplitudes, they tended to originate from a wider cortical area-this is especially 
evident in layer 5 cells, in which we detected significant inputs from supragranular layers (Fig. 2A2,B2).

We hypothesized that a specific type of interneuron is responsible for shortlatency input. Specifically, the perisomatic origin of slIPSCs suggested that they might be mediated by FS interneurons, whose cell bodies are usually located close to that of their postsynaptic partners (and whose synapses mainly target pyramidal cell somata) (Thomson et al., 1996; Tamás et al., 1997; Xiang et al., 2002). FS interneurons in rodent neocortex have a high probability of synapsing onto each other (Gibson et al., 1999; Galarreta and Hestrin, 2002). Therefore, to provide further evidence that sIIPSCs might reflect FS cell inputs, we tested whether they might also be observed in postsynaptic FS interneurons. FS and non-fast-spiking (non-FS) interneurons were identified based on their nonpyramidal soma, smaller size, lack of a thick apical dendrite, and the waveform of extracellularly recorded action potentials. As the use of a cesium-based internal solution and the sodium channel blocker QX314 precluded cell identification based on current-clamp spike properties, we recorded action potentials evoked by glutamate uncaging onto the cell's soma in cellattached mode before acquiring whole-cell configuration (Fig. 3A). We verified this approach in a separate set of experiments with potassium-based recording solutions by comparing extracellular action potential waveforms to those subsequently obtained via whole-cell current-clamp recordings in the same cells. FS and non-FS interneurons had significantly different action potential waveforms. FS interneurons had briefer spike durations than either pyramidal cells or non-FS interneurons (FS: $1.15 \pm$ $0.07 \mathrm{~ms}, n=14$; non-FS: $2.16 \pm 0.18 \mathrm{~ms}, n=13$; pyramidal: $3.69 \pm 0.32, n=14, p<0.01$ for all comparisons, ANOVA). The quotient of the maximum positive divided by the maximum negative deflection differed in the three cell types (FS: $0.42 \pm 0.02 \mathrm{~ms}$, $n=14$; non-FS: $0.25 \pm 0.02 \mathrm{~ms}, n=13$; pyramidal: $0.15 \pm 0.01$, $n=14, p<0.01$ for all comparisons, ANOVA). Additionally, non-FS interneurons had a characteristic secondary "bump" in the positive deflection, which was used as a third component in cell classification. The "bump" was not investigated in more detail but probably reflects complex spike repolarization because of sequential activation of multiple types of potassium channels. Taking these characteristics together, we were able to classify $>90 \%$ of all neurons as pyramidal, FS, or non-FS (Fig. $3 B$ ). We recorded inhibitory synaptic input maps from 12 interneurons (4 FS, 8 non-FS) and analyzed them based on IPSC latencies as we had done for pyramidal cells. FS interneurons, like pyramidal cells, received strong inhibitory inputs within the first $10 \mathrm{~ms}$, and nearly all IPSCs originated within a $250 \mu \mathrm{m}$ radius surrounding the soma, indicating that presynaptic cell bodies were located near the recorded cell and likely extended only a short axonal projection to it (Fig. 3C1). These input maps are in qualitative agreement with those reported for FS interneurons in layer 2/3 of mouse somatosensory cortex (Xu and Callaway, 2009). Non-FS interneurons, however, received both short and regular latency IPSCs from a much wider cortical area spanning layers $2-6$, and most inputs had latencies of $>10 \mathrm{~ms}$ (Fig. 3C2). Consistent with the heterogeneous nature of non-FS interneurons (Markram et al., 2004; Wonders and Anderson, 2006; Xu and Callaway, 2009), we found two distinct types of excitatory input maps onto non-FS cells (supplemental Fig. 1, available at www.jneurosci.org as supplemental material). However, the IPSC input maps did not differ systematically between these two classes of non-FS cells (data not shown).

\section{IPSC onset latencies in pyramidal cells and FS interneurons differ from non-FS interneurons and from EPSC onset latencies in all cell types}

Next, we constructed peristimulus time histograms of IPSCs and EPSCs in pyramidal cells, FS interneurons, and non-FS interneurons. Contrary to the synaptic input maps shown in Figures 2 and 3 , this analysis considers only the timing of individual events, regardless of their amplitude. Figure $4 A$ shows example IPSC traces of a layer 5 pyramidal cell, an FS interneuron, and a non-FS interneuron, suggesting longer onset latencies in the non-FS interneuron. The quantification of IPSCs in all neurons of the specific subtype confirmed this (Fig. $4 B, D$ ): The peak IPSC onset latencies in pyramidal cells and FS interneurons were 6.61 and $5.42 \mathrm{~ms}$, respectively, compared with $10.17 \mathrm{~ms}$ in non-FS interneurons. Peak EPSC latencies were similar in all three neuronal types (pyramidal: $11.36 \mathrm{~ms}$, non-FS: $12.54 \mathrm{~ms}$, and FS: $11.95 \mathrm{~ms}$ ) (Fig. 4C,E). Thus, although there were no pronounced differences in EPSC latencies in the three cell types, IPSCs had shorter 

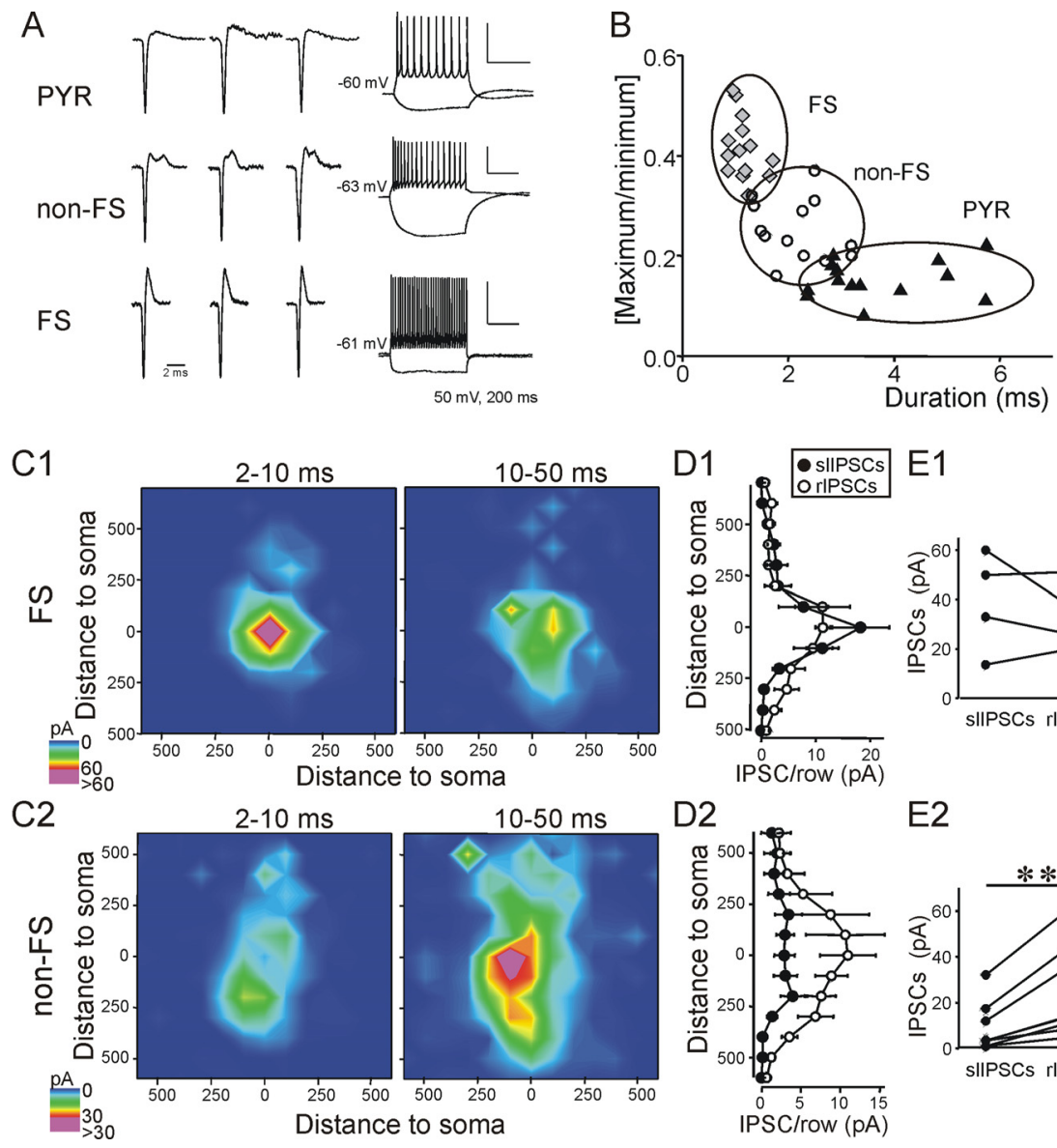

Figure 3. Inhibitory input maps to FS and non-Fs interneurons. $\boldsymbol{A}$, Left, Cell-type identification. Cell-attached recordings of action potentials evoked by glutamate uncaging onto somata of layer 5 cells. Three examples each from pyramidal cells (top left), non-FS interneurons (center left), and FS interneurons (bottom left). Right, Response to hyperpolarizing ( $-200 \mathrm{pA})$ and depolarizing $(+200 \mathrm{pA})$ current injections in the three cell types, used to validate the identification method. Intracellular recordings are from the same cells as the third extracellularly recorded action potential in each row. B, Duration (see Materials and Methods) of each extracellularly recorded action potential versus the ratio of the maximum positive to maximum negative deflection. Neuronal types mostly segregate into distinct clusters. For additional identification, we used the presence of a pronounced secondary "bump" in the positive deflection (characteristic of non-FS interneurons) and morphology (to distinguish pyramidal from nonpyramidal cells). C, Input maps for sIIPSCs (left panels) and rIPSCs (right panels) in four FS interneurons (C1) and eight non-FS interneurons (C2) in layer 5. Cumulative IPSC amplitudes were analyzed and depicted as in Figure 4. D, Averaged inputs for $100 \mu \mathrm{m}$ rows for sIIPSC (black circles) and rISPC (open circles) cells in FS interneurons (D1) and non-FS interneurons (D2). Non-FS interneurons received inputs from a much wider range of cortical lamina than FS cells, which tend to receive input mainly from cells in the same layer (V). E, Average cumulative sIIPSC and rIPSC amplitude evoked from each spot within a $200 \mu \mathrm{m}$ of each cell's soma. SIISPC input was similar to rIPSC input in FS interneurons (E1), but non-FS interneurons received significantly less sIIPSC than rIPSC input (E2).

latencies in pyramidal cells and FS interneurons compared with non-FS interneurons. This suggests that PSC latency distributions are governed largely by properties of the presynaptic neurons, and more specifically, that FS interneurons and pyramidal neurons receive a large proportion of inhibitory inputs from a common class of interneurons.

\section{Are sIIPSCs elicited by somatic or presynaptic excitation?}

Inhibitory presynaptic terminals can express kainate receptors (Clarke et al., 1997; Jiang et al., 2001; Kang et al., 2004; Jin and Smith, 2007; Ren et al., 2007) that might be activated by LSPS. A recent report indicates that layer $2 / 3$ pyramidal cells target such kainate receptors on presynaptic terminals of FS to pyramidal cell synapses. Their activation causes calcium-dependent GABA release, providing a mechanism for rapidly coupling pyramidal cell activity to inhibition in nearby pyramidal cells (Ren et al., 2007).
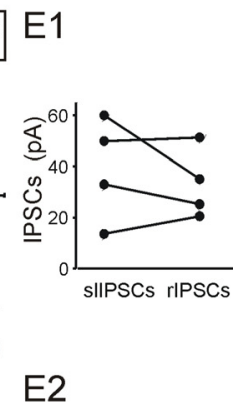

Thus, slIPSCs might result from direct LSPS activation of presynaptic kainate receptors. The facts that sIIPSCs have very short latencies and are evoked from locations near the postsynaptic target argue for this possibility. Alternatively, sIIPSCs could be caused by somatic depolarization of interneurons, via fast glutamate receptors located on their somata. If sIIPSCs were mediated by activation of presynaptic kainate receptors (1) they would be preferentially blocked by kainate receptor preferring antagonists (greater degree of block than would be expected for AMPA receptor-mediated EPSCs); (2) sIIPSC latency would be very brief, on the order of that expected for direct terminal depolarization and subsequent synaptic delay $(<2$ ms total; see Discussion), rather than that expected for FS interneuron depolarization and spike initiation followed by propagation and synaptic delays (see Fig. 8); and (3) they would be evoked together with direct activation of the recorded cell, since the release site must necessarily overlap with the recorded cells' soma.

\section{slIPSCs are not preferentially affected by kainate receptor blockade}

To test whether slIPSCs were caused by direct glutamate release onto presynaptic kainate receptors on FS interneuron to pyramidal cell synapses, we tested their sensitivity to the selective kainate receptor blocker UBP301 $(50 \mu \mathrm{M})$ and compared it to the effects on electrically evoked EPSCs. At the concentration used, we expected near complete block of kainate receptors $\left(\mathrm{K}_{\mathrm{D}}=5.94 \mu \mathrm{M}\right)$ (More et al., 2003). UBP301 has only an $\sim 30$-fold preference for kainate over AMPA receptors (apparent $\mathrm{IC}_{50 \text { (AMPA) }}=164 \mu \mathrm{M}$ in a neonatal rat spinal cord preparation) (More et al., 2003). Although the precise affinities of this antagonist for synaptic AMPA and kainate receptors in our preparation is not known (because of differences in tissue, age, and preparation, and potential differences in receptor subtype expression), we expected to see a partial blockade of AMPA receptor-mediated responses at the concentrations used. For this reason, we used block of electrically evoked EPSCs in pyramidal cells as a control, as postsynaptic responses are mainly AMPA receptor mediated in rats at the ages used in this study (Ali et al., 2001, 2003; Campbell et al., 2007). If slIPSCs were dependent on kainate receptor activation, they would be attenuated by UBP301 more strongly than EPSCs. Figure 5, $A 1, B 1$ and $C 1$, shows results from 5 cells each in which the effect of UBP301 on slIPSCs and EPSCs was assayed. The amplitude of sIIPSCs was reduced to $39.4 \pm 9.2 \%$ of control in the presence of UBP301, and EPSC amplitudes were reduced to similar extent: $36.9 \pm 3.6 \%$ of control $(p<0.05)$ (Fig. 5C1). The moderate degree of PSC block and the similar effect on EPSCs and sIIPSCs indicates that sIIPSCs are largely independent of kainate receptor activation. Ren et al. 
(2007) showed immunohistochemically that presynaptic kainate receptors in FS cell to pyramidal cell terminals contain the GluR5 subunit. To specifically test whether GluR5-containing kainate receptors are involved in slIPSC generation, we performed another set of experiments using the GluR5 antagonist UBP302. Unlike UBP301, UBP302 (the active enantiomer of UBP296) exerts no significant block of AMPA receptors (More et al., 2004). UBP302 $(30 \mu \mathrm{M})$ blocked neither slIPSCs nor electrically evoked EPSCs (Fig. $5 A 2, B 2, C 2)$. In the presence of UBP302, the average sIIPSC amplitude was $93.4 \%$ of control $(p>0.5 ; n=7)$, and the average EPSC amplitude was $108.4 \%$ of control $(p>0.1 ; n=6)$, indicating that slIPSCs (just like EPSCs) are not dependent on kainate receptors containing the GluR5 subunit.

To further confirm these results, we performed similar experiments using GYKI-52466. This selective AMPA receptor blocker has an $\sim 30$-fold selectivity for AMPA over kainate receptors, with an $\mathrm{IC}_{50}$ $\sim 20 \mu \mathrm{M}$ at AMPA receptors and $>200 \mu \mathrm{M}$ at kainate receptors (Paternain et al., 1995; Wilding and Huettner, 1995). EPSC amplitudes were expected to be attenuated by $80-90 \%$ in the presence of $50 \mu \mathrm{M}$ GYKI52466 , and if slIPSCs were dependent on kainate receptor activation, they would be blocked to a much lesser degree. Figure $5 C 3$ shows that EPSC amplitudes were indeed significantly reduced $(22.7 \pm 5.2 \%$ of control, i.e., in good agreement with the expected values; $p<0.005, n=4$ ) and that slISPCs were blocked to a slightly larger degree $(6.7 \pm 1.1 \%$ of control; $p<0.01$, $n=5$ ) The larger block of slIPSCs compared with EPSCs likely results from a reduction in AMPA receptor- dependent depolarization of presynaptic neurons, such that a large proportion of responses become subthreshold for triggering action potentials. Together, these results show that the pharmacological profile of the glutamatergic component of slIPSCs did not differ significantly from that of EPSCs. Thus, we did not find evidence for a significant involvement of kainate receptors.

\section{FS interneuron spike latencies are consistent with slIPSCs resulting from somatic depolarization}

Next, we sought to determine whether sIIPSC latencies were consistent with spike latencies of FS interneurons. We obtained cellattached recordings from FS and non-FS interneurons, and pyramidal cells and recorded action potentials evoked by uncaging glutamate directly onto somata (Fig. 6A). The stimulation intensities used were similar to those used in mapping experiments $(200-600 \mu \mathrm{s})$. FS interneurons had significantly shorter spike latencies than non-FS or pyramidal neurons (Fig. 6C) (FS: $3.13 \pm$ $0.41 \mathrm{~ms}, n=18$; non-FS: $5.50 \pm 0.61 \mathrm{~ms}, n=42$; pyramidal: $7.69 \pm 0.66, n=19$; FS vs non-FS: $p<0.05$; FS vs PYR: $p<0.01$; PYR vs non-FS: not significant; ANOVA). The shortest recorded spike latencies were $1.15 \mathrm{~ms}$ for FS interneurons, $1.50 \mathrm{~ms}$ for non-FS, $20 \mathrm{~ms}$ ).
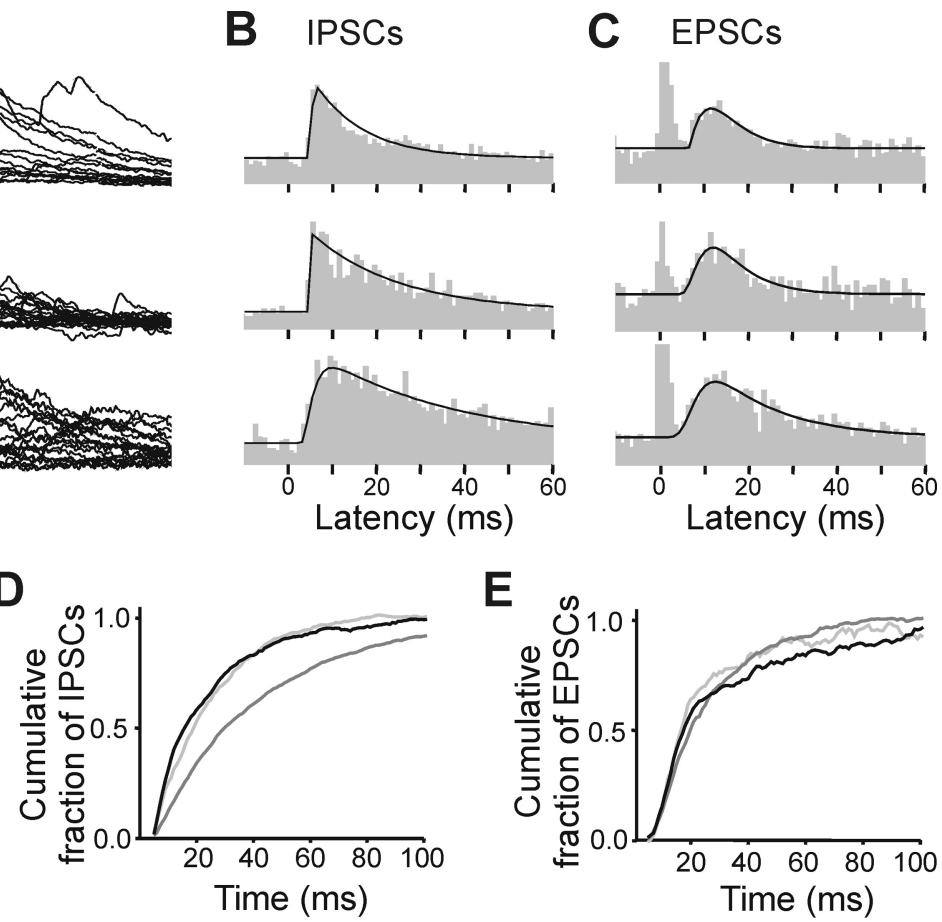

Figure 4. PSC peristimulus time histograms. $\boldsymbol{A}$, Examples of LSPS-evoked ISPCs in a pyramidal cell (top), an FS interneuron (center), and a non-FS interneuron (bottom), all in layer 5. Stimulus time is indicated with a dotted line. $\boldsymbol{B}$, Left, Histograms

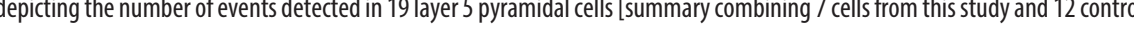
Black lines indicate fits to the following equation (the "pulse" function in Origin 7): $y=y_{0}+A\left(1-e^{-\left(x-x_{0}\right) / t_{1}}\right)^{p *} e^{-(} x-$ , $\left.x_{0}\right), y$-offset (background); $x_{0}$, center; $A$, amplitude; $p$, power; $t_{1}$ and $t_{2}$, decay constants. Fits were used to calculate $D$, but for EPSCs. There were no consistent differences in median EPSC latency between the three cell types (PYR, $18 \mathrm{~ms}$; FS, $17 \mathrm{~ms}$;

non-FS interneurons, and $3.2 \mathrm{~ms}$ for pyramidal cells (Fig. 6C). The peristimulus time histograms in Figure 4 indicate that the earliest time at which the number of IPSCs is elevated above background levels is between 4 and $6 \mathrm{~ms}$ after the uncaging pulse for all cell types, whereas the EPSCs rises above background levels at a later point in time, between 8 and $10 \mathrm{~ms}$ after the photostimulation. Given the minimum observed spike latency in FS interneurons ( $1.15 \mathrm{~ms}$ ) and a synaptic and propagation delay of $2-5$ ms (see Fig. 8), an IPSC latency of as little as $3.15 \mathrm{~ms}$ would be consistent with somatic depolarization of FS interneurons. FS interneuron synapses target the soma or proximal apical dendrite of pyramidal cells, whereas non-FS and pyramidal cell synapses target more distal locations (Thomson et al., 1996; Tamás et al., 1997; Xiang et al., 2002). The resulting shorter IPSC propagation distance would further lead to a shortening of the spike-to-IPSC interval for FS cells.

In a subset of cells, multiple spikes were evoked by glutamate uncaging (Fig. 6A). The interspike interval was $4.72 \pm 0.40 \mathrm{~ms}$ for FS interneurons $(n=7)$ and $10.77 \pm 0.93 \mathrm{~ms}$ for non-FS interneurons $(n=8)$. We also observed that the rising phase of sIIPSCs displayed steps, suggesting the summation of asynchronous individual events (see example traces in Fig. 6 B; also evident in Fig. 7). We sought to further explore whether repetitive firing 


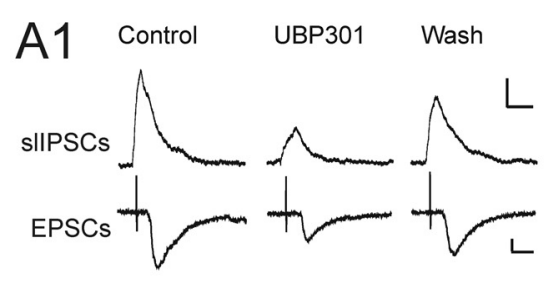

B1
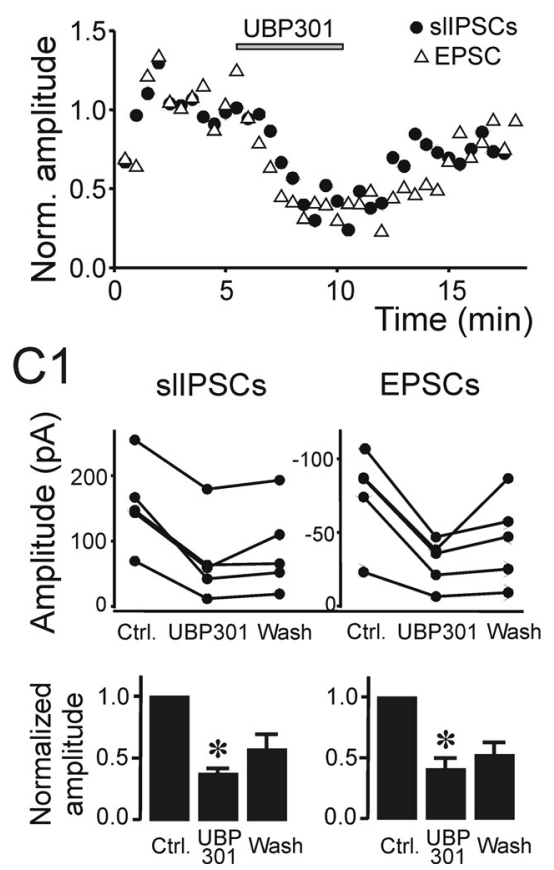

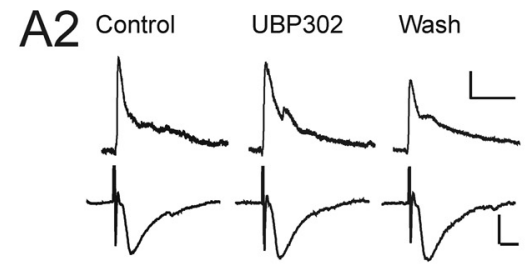

B2
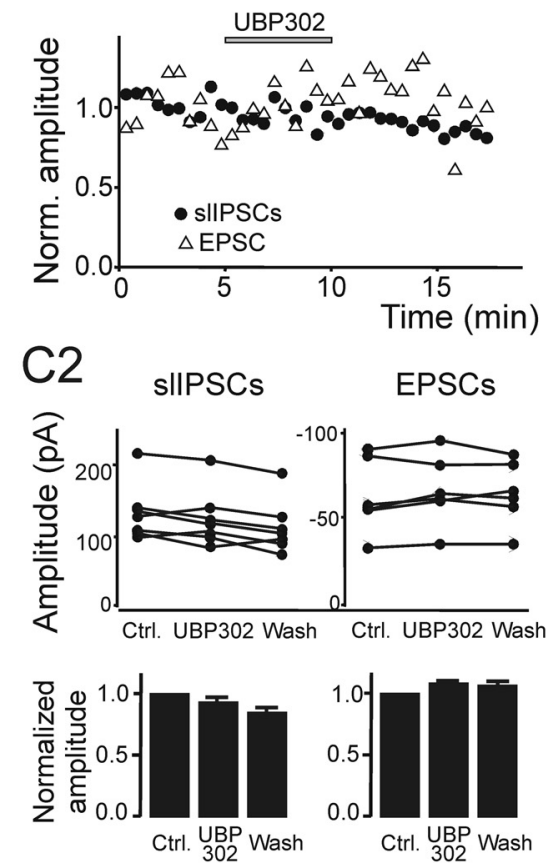

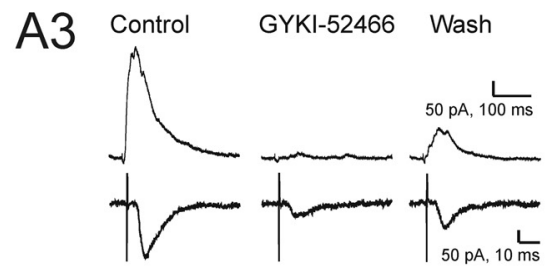

B3

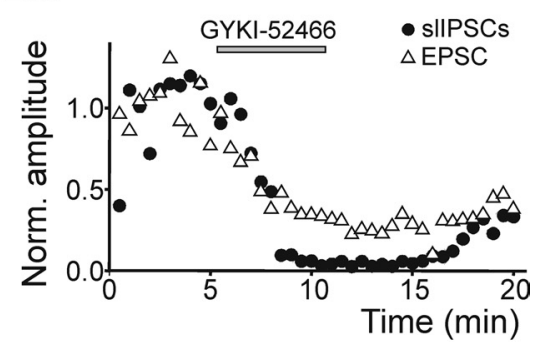

C3

sllPSCs

EPSCs
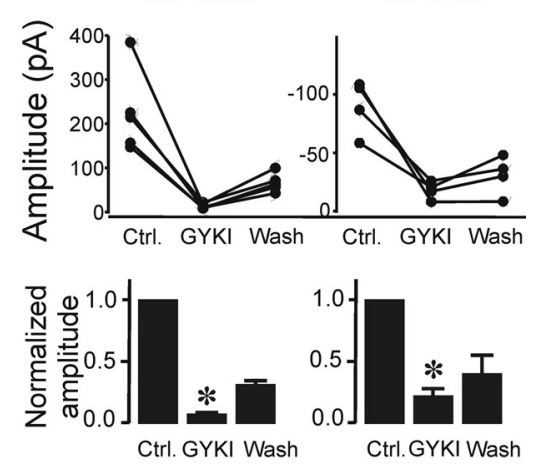

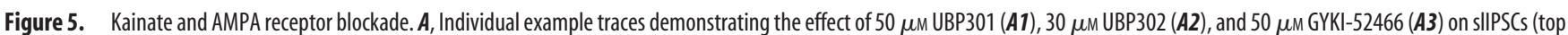
row) and electrically evoked EPSCS (bottom row). The traces in each row were recorded during the control period (left), in the presence of the blocker (middle), and toward the end of the wash (right). UBP301 and GYKI-52466 decreased sIIPSC and EPSC amplitudes, whereas UBP302 did not. B, Time course of UBP301 (B1), UBP302 (B2), and GYKI-52466 (B3) action. slIPSCs (black circles) and EPSC (open triangles) amplitudes for the recordings from which the example traces in $\boldsymbol{A}$ were taken. C, Effects of UBP301 (C1), UBP302 (C2), and GYKI-52466 (GYKl; C3) on the amplitudes of sIIPSCs (left panels) and EPSCS (right panels). UBP301 and GYKI-52466 reversibly reduced PSC amplitudes in each cell tested. Summary data in bottom panels shows normalized sllPSC and EPSC amplitudes. Unlike UBP301 and GYKI-52466, UBP302 had no significant effect on sIIPSC and EPSC amplitudes.

of FS interneurons could account for the stepwise rising phase of sIIPSCs. LSPS was performed using the $63 \times$ instead of the $5 \times$ microscope objective to more tightly focus the region of uncaging and limit (but not necessarily eliminate) the possibility of simultaneously activating multiple presynaptic cells. The histogram in Figure $6 D$ shows interevent intervals for spikes in FS and non-FS interneurons, and for sIIPSCs in pyramidal cells. Seventeen percent of IPSCs $(11 / 62)$ had intervals of $<3.15 \mathrm{~ms}$ - the fastest recorded interspike interval-suggesting that they were caused by inputs from two separate presynaptic interneurons. However, $45 \%(28 / 62)$ of inter-ISPC intervals were within the range of interspike intervals in FS interneurons (i.e., 3.15-6.68 ms). This suggests that a significant proportion of individual composite slIPSCs result from repetitive spiking of the same presynaptic FS interneuron.

\section{slIPSCs are not always associated with concurrent direct activation}

"High-resolution" maps acquired using the $63 \times$ microscope objective, with grid spacings of $10-15 \mu \mathrm{m}$, were used to determine how frequently sIIPSCs and direct excitation were evoked from the same spot. An example map is shown in Figure 7. The maps depicting direct activation (inward current with latency of $<3$ ms) (Fig. 7B) and slIPSCs (Fig. 7C) show that the two types of activation generally exhibited overlapping patterns. However, there were instances in which slIPSCs were evoked at sites without direct excitation (see example trace Fig. 7C). Figure $7 D$ shows more examples of the three types of excitation, direct only (top), sIIPSC only (middle), and both (bottom). The summary data for maps from 6 layer 5 pyramidal neurons shows that slIPSC and direct activation coincided at $57 \%$ of stimulation sites, whereas direct activation alone occurred at nearly $28 \%$ of sites, and stimulation at $15 \%$ of sites resulted in sIIPSCs only (Fig. $7 E$ ). This would be incompatible with direct presynaptic terminal activation, which would necessarily also directly activate the postsynaptic cell.

\section{Discussion}

In this study, we investigated $\mathrm{GABA}_{\mathrm{A}}$ receptor-mediated inputs evoked by LSPS in neocortical pyramidal cells, FS, and non-FS interneurons. In pyramidal cells, the strongest LSPS-evoked IPSCs had a latency of $<10 \mathrm{~ms}$ and originated within a $300 \mu \mathrm{m}$ radius of the recorded cell. IPSCs with longer latencies originated from essentially all cortical lamina. Distinct patterns were seen for LSPS-evoked IPSCs in two different classes of interneurons: inputs onto FS interneurons originated mostly from sites close to the recorded cell's soma and tended to have short latencies, whereas IPSCs in non-FS interneurons had longer latencies and 
came from all cortical lamina. FS interneurons have a high connection probability with other FS interneurons (Gibson et al., 1999; Bacci et al., 2005). Thus, the similarity in IPSC latencies and sites of origin in FS interneurons and pyramidal cells suggests that slIPSCs in pyramidal cells mainly reflect FS to pyramidal cell connections.

IPSC latencies in pyramidal cells were shorter than EPSC latencies, leading us to test the hypothesis that LSPS-evoked sIIPSCs result from activation of kainate receptors on inhibitory presynaptic terminals. Such receptors modulate IPSCs at a number of central synapses. This can lead to facilitation (Jiang et al., 2001; Kang et al., 2004; Ren et al., 2007) or inhibition (Clarke et al., 1997; Ali et al., 2001; Jin and Smith, 2007) of GABAergic neurotransmission. For example, activation of presynaptic kainate receptors on striatopallidal synapses inhibits GABA release via a PKC-dependent mechanism (Jin and Smith, 2007). However, presynaptic kainate receptors on inhibitory terminals onto neocortical pyramidal cells can, when activated by glutamate released from another pyramidal cell, induce pyramidal to pyramidal cell inhibition (Ren et al., 2007). At these synapses calcium influx through kainate receptors results in calcium-dependent calcium release from intracellular stores (Mathew and Hablitz, 2008). The short onset latencies of sIIPSCs and their perisomatic region of origin would appear to support the hypothesis that glutamate release via LSPS directly activates kainate receptors on inhibitory presynaptic terminals onto pyramidal cells, causing GABA release. Alternatively, slIPSCs could arise in essentially the same way that LSPS-evoked EPSCs do: by somatic depolarization (in this case of interneurons), action potential generation, and subsequent neurotransmitter release. Last, action potential generation in pyramidal cells could lead to glutamate release and activation of presynaptic kainate receptors, leading to IPSCs in the recorded pyramidal cell, essentially as in the paired recordings described by Ren et al. (2007). The onset latency (significantly shorter than for LSPS-evoked pyramidal to pyramidal cell EPSCs) strongly argues against the last possibility, as does the average failure rate of pyramidal to pyramidal cell inhibition of $\sim 10 \%$ (Ren et al., 2007). Although our approach did not allow us to ascertain whether action potentials were actually generated, we observed essentially no failures in cells in which we repeatedly evoked slIPSCs from the same spot.

The data we present support a model of somatic depolarization and spike generation of interneurons rather than presynaptic depolarization (depolarization of presynaptic terminals). For one, sIIPSCs were no more sensitive to kainate receptor blockade than electrically evoked synaptic EPSCs (Fig. 5). Since EPSCs are AMPA receptor mediated (see Results), slIPSCs appear to be, too. Second, sIIPSC latency is in better agreement with somatic depo-
B

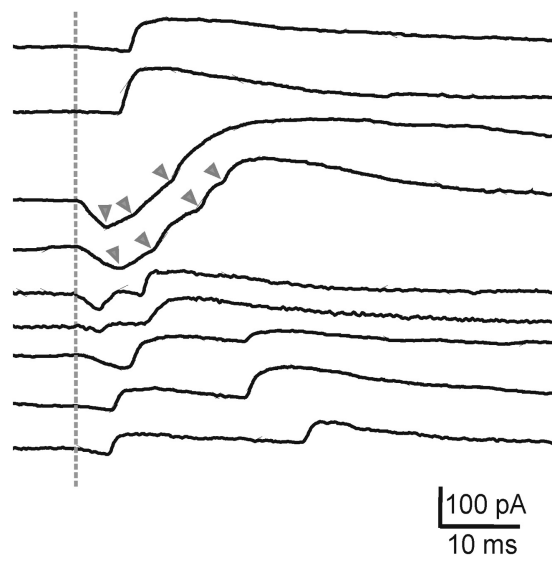

D

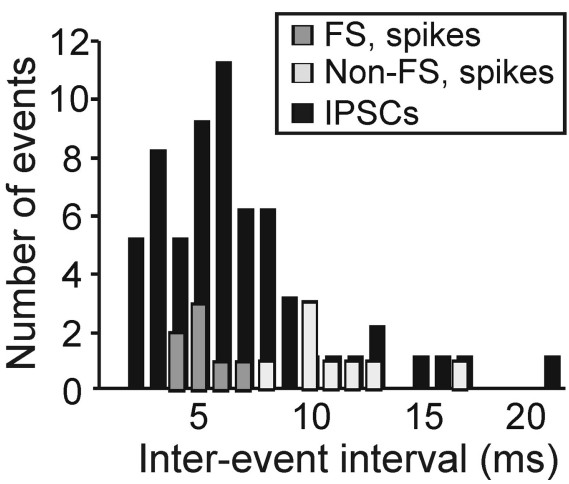

Figure 6. Spike latencies and interevent intervals. $\boldsymbol{A}$, Example traces recorded in cell-attached mode from an FS interneuron intervals for spikes in FS interneurons (dark gray), non-FS interneurons (light gray) and sIIPSCs in pyramidal cells (black) in $1 \mathrm{~ms}$ bins. Most inter-IPSC intervals fell within the range of interspike intervals recorded in FS interneurons.

larization of FS interneurons. The schema in Figure 8 summarizes the possible scenarios and the resulting expected latencies. Somatic depolarization of the presynaptic FS neuron is depicted in Figure $8 \mathrm{~A}$. As shown in this study, glutamate release onto an FS cell's soma leads to suprathreshold depolarization and action potential generation with latencies of as little as $1.15 \mathrm{~ms}-90 \%$ of FS interneurons generated the first spike between 1.2 and $5 \mathrm{~ms}$ after LSPS. Thus, we applied an estimate of $1.15-5 \mathrm{~ms}$ for the latency to spike. Based on latencies of electrically evoked synaptic responses, we used an estimate of $2-5 \mathrm{~ms}$ for action potential propagation to the synapse, synaptic delay, and propagation of the IPSC to the soma of the recorded cell. A maximum of $1 \mathrm{~ms}$ of this time is likely needed for PSC propagation to the recorded cell's soma: according to previous studies (Schubert et al., 2001; Brill and Huguenard, 2008), the propagation delay of direct responses evoked by LSPS in pyramidal cell dendrites within $100 \mu \mathrm{m}$ from the soma is $\leq 1 \mathrm{~ms}$. FS cells synapse onto the soma or proximal dendrite of pyramidal cells; therefore, IPSCs propagation distance will be short. Based on these results, we expect IPSCs resulting from somatic depolarization of FS interneurons to have average latencies of 3.15-10 ms. Presynaptic depolarization (Fig. 

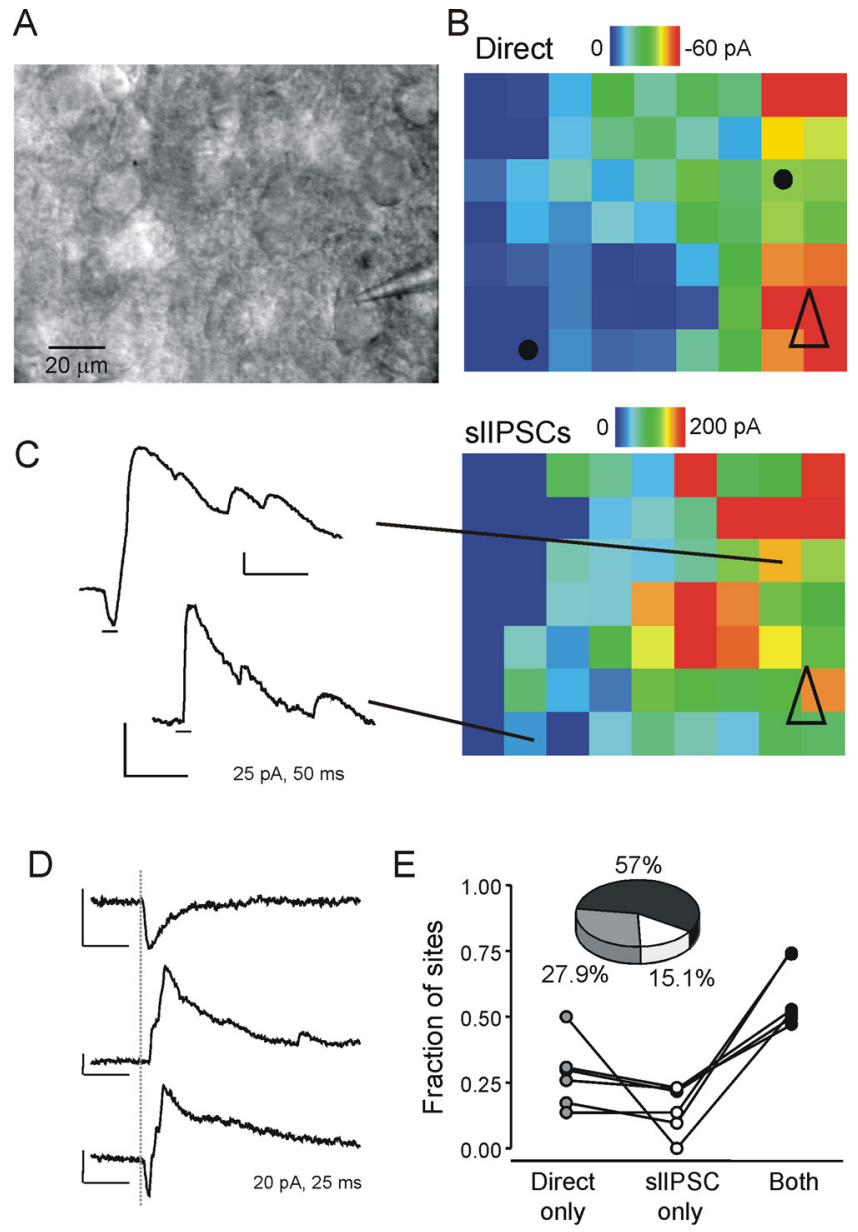

Figure 7. Lack of complete coincidence between direct activation and sIIPSCS. A, Image of slice obtained with $63 \times$ objective, showing the patch pipette during whole-cell recording from a pyramidal neuron in the lower right-hand corner. $\boldsymbol{B}$, Map of direct activation (peak negative amplitude within the first $3 \mathrm{~ms}$ ) from the cell shown in $\boldsymbol{A}$. Open black triangle indicates position of the soma. Black dots indicate position from which the example traces in C were evoked. C, Right, sllPS c map from the same cell showing the cumulative amplitude of all outward currents with latencies of 2-10 ms. Left, Example traces showing coincident direct activation and sIIPSC (top) or slIPSC alone (bottom). Short black lines underneath the traces indicate the first $10 \mathrm{~ms}$ after stimulus. $\boldsymbol{D}$, Another set of example traces from a different cell showing either simple direct activation (top), isolated sIIPSCS (center), or coincident activation of both types of events (bottom). Gray dotted line indicates time of laser stimulus. $\boldsymbol{E}$, Summary data from six maps acquired at high resolution using the $63 \times$ objective, showing the proportion of sites from which only direct activation, only slIPSCs or both types of activation were evoked.

$8 B$ ) omits somatic depolarization and spike propagation to the synapse, but retains synaptic delay and PSC propagation to the recorded cell's soma. We assumed that depolarization resulting from kainate receptor activation has a similar time course than presynaptic depolarization during action potential invasion. Thus, presynaptic depolarization will result in shorter average IPSC latencies of $2-5 \mathrm{~ms}$. The peak of the sIIPSC latency distribution was $6.61 \mathrm{~ms}$ (Fig. $4 \mathrm{~B}$ ), and is therefore in better agreement with the scenario of somatic depolarization. In contrast, the calculated latency for events evoked by presynaptic depolarization is in good agreement with the latency of 2-3 ms reported by Ren et al. (2007). We thus conclude that onset latencies of slIPSCs are consistent with somatic depolarization of FS interneurons rather than depolarization of presynaptic terminals.

In addition, sIIPSCs were not necessarily evoked together with direct glutamatergic activation of the postsynaptic cell. If slIPScs were caused by activation of kainate receptors on interneuron to

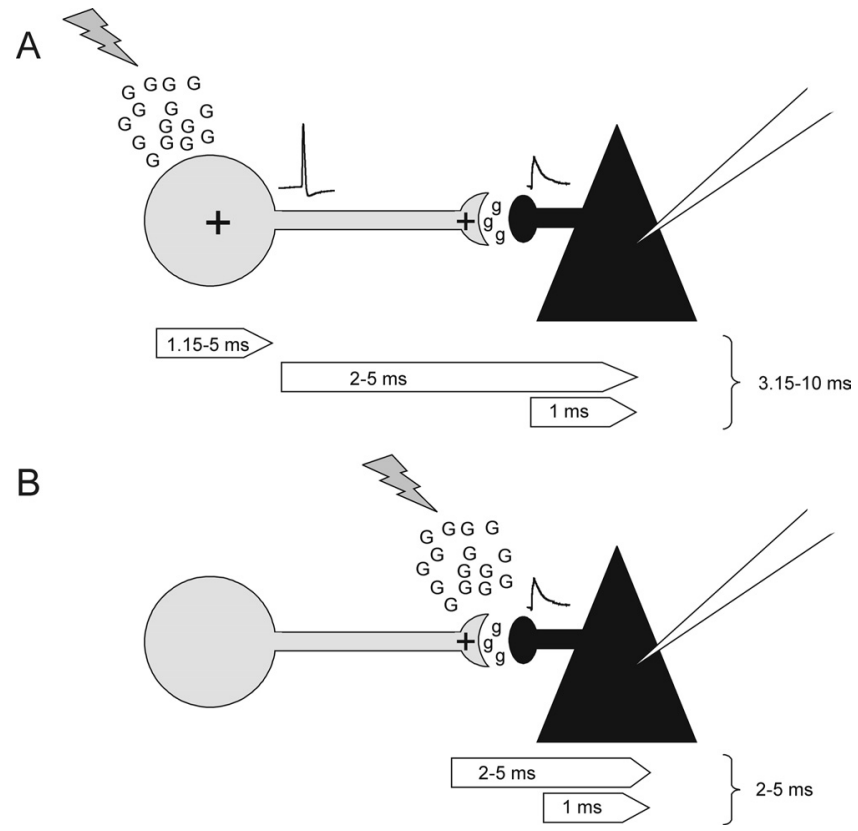

Figure 8. Possible scenarios for the origin of sllPSCS. A, "Somatic depolarization." sllPSC evoked by somatic depolarization of an FS interneuron (gray). Glutamate (G) is released by LSPS leading to action potential generation within $1.15-5 \mathrm{~ms}$, causing release of GABA (g) at an FS to pyramidal cell synapse. The IPSC propagates to the soma of the pyramidal cell (black) where it is recorded. Action potential propagation, synaptic delay, and propagation of the IPSC to the pyramidal cell soma is estimated to take $\sim 2-5 \mathrm{~ms}$, with $\leq 1 \mathrm{~ms}$ needed for IPSC propagation. According to this model, the minimum latency of IPSCs generated through somatic depolarization would be $3.15 \mathrm{~ms}$. B, "Presynaptic depolarization." sllPSC evoked by depolarization of the presynaptic terminal. Glutamate is released onto the FS to pyramidal cell synapse and causes calcium-dependent GABA release via activation of presynaptic kainate receptors. We estimated this to take the same time as presynaptic depolarization after action potential invasion and subsequent synaptic delay. The IPSC then propagates to the pyramidal cell soma as in model $\boldsymbol{A}$. According to this model, the minimum latency of IPSCs generated through direct synaptic depolarization would be $2 \mathrm{~ms}$. The observed peak latency of sllPSCs of $6.61 \mathrm{~ms}$ (Fig. $4 B$ ) is in better agreement with somatic depolarization presented in $\boldsymbol{A}$.

pyramidal synaptic terminals and given an estimated uncaging half width of $20 \mu \mathrm{m}$ when the laser pulse is delivered through the $63 \times$ objective (see Materials and Methods), LSPS at such locations would necessarily cause glutamate release onto significant portions of the dendritic compartment of the recorded cell, which would produce significant direct activation of the postsynaptic cell. This is inconsistent with the failure to coactivate both presynaptic and postsynaptic responses from as many as $15 \%$ of uncaging sites (Fig. 7).

Other indirect evidence also argues against kainate receptordependent GABA release: the interval between individual components of summated sIIPSCs is consistent with the interspike intervals of FS interneurons. Although we cannot rule out that summated IPSC components are caused by asynchronous activation of more than one presynaptic cell, the close correspondence of interevent and interspike intervals strongly suggests that a large proportion in fact arises from repeated firing of single presynaptic FS interneurons, which is a common occurrence with our LSPS protocol (Fig. 6A). We also show that slIPSCs were dependent on voltage-gated sodium channels, i.e., they were blocked by TTX. However, Mathew and Hablitz (2008) demonstrated that kainate receptor-dependent GABA release occurs via calciumdependent calcium release from intracellular stores and is not dependent on action potentials. In fact, the frequency of action potential independent IPSCs in pyramidal cells was increased in the presence of kainate. 
In summary, LSPS does not evoke detectable GABA release via activation of presynaptic kainate receptors. We have shown previously that LSPS preferentially activates a pool of nonsynaptic glutamate receptors (Brill and Huguenard, 2008). Thus, we speculate that synapses are not as readily accessible to exogenously released glutamate as the extrasynaptic compartment, probably because they are effectively shielded from the extrasynaptic environment by astrocytes (Oliet et al., 2001; Syková, 2004). This might explain why we did not observe pyramidal cell inhibition mediated by presynaptic kainate receptors on inhibitory terminals, as described by Ren et al. (2007). In addition, we cannot exclude the possibility that presynaptic kainate receptormediated inhibition is less prevalent rat somatosensory cortex (used in this study) than in mouse visual cortex [used in the study by Ren et al. (2007)].

Other studies on inhibitory input maps (Dantzker and Callaway, 2000; Kumar et al., 2007; Xu and Callaway, 2009) have used detection windows starting $10 \mathrm{~ms}$ after laser stimulus, to avoid including kainate receptor evoked inhibition during LSPS stimulation of presynaptic terminals, but our results suggest that a significant proportion of inhibitory events occur with latencies $<10 \mathrm{~ms}$

The distinction between two types (from presumptive FS vs non-FS interneurons) of input based on latency alone is not absolute. Studies using paired recordings have shown that FS interneuron onto pyramidal cell IPSCs are significantly larger than non-FS onto pyramidal cell IPSCs (Xiang et al., 2002; Yoshimura and Callaway, 2005). This will bias the analysis of LSPS data toward detection of FS interneuron mediated IPSCs. We should also caution that the latency criteria would favor detection of perisomatic inputs, since inputs from more distally localized synapses will have a longer propagation delay. However, dividing LSPS-evoked EPSCs into short and long latency inputs resulted in essentially identical maps (data not shown), suggesting that IPSC latencies indeed reveal inputs from different interneuronal classes.

Pyramidal cells, FS interneurons, and non-FS interneurons had distinct spikes latencies when activated by somatically targeted LSPS. Under physiological conditions, neurons integrate synaptic input that typically arrives within the dendritic compartment, and our experiments do not reveal how efficiently this integration proceeds in the three types of neurons. However, it does suggest that similar degrees of somatic depolarization lead to more rapid spike generation in FS interneurons. In this context, it should be pointed out that maximal direct currents evoked by LSPS onto the soma during mapping of inhibitory inputs did not differ significantly in FS and non-FS cells (FS: $606 \pm 56 \mathrm{pA}$, $n=4$; non-FS: $650 \pm 87 \mathrm{pA}, n=11$ ). Mechanisms for the accelerated excitation-spike coupling in FS interneurons may include expression and kinetics of sodium and potassium channel subunits (Martina and Jonas, 1997; Martina et al., 1998). The fast excitation-spike coupling is also in agreement with the role of FS interneurons in the generation of gamma oscillations (Bartos et al., 2007).

The division of interneurons into FS and non-FS is a simplification. FS interneurons are subdivided into basket cells, which can be subdivided further mainly based on their morphology (Markram et al., 2004) and chandelier cells (Szentágothai and Arbib, 1974). FS interneuron somata are usually located close to the somata of their postsynaptic partners (Yoshimura and Callaway, 2005), although long-range FS to pyramidal cell connections exist (Somogyi et al., 1983). A major difference between basket and chandelier cells is that the former target pyramidal cell so- mata and proximal dendrites (Marin-Padilla, 1972), whereas the latter target axons initial segments (Somogyi, 1977). Chandelier cells only comprise a small proportion of FS interneurons (Markram et al., 2004), and thus likely do not represent a major source of sIIPSC input. The axon initial segment of pyramidal cells has a depolarized chloride reversal potential (Khirug et al., 2008); therefore, chandelier cell to pyramidal cell IPSCs can be depolarizing, and lead to long-lasting network activation (Szabadics et al., 2006; Molnár et al., 2008). To understand the network consequences of slIPSCs, it will be important to determine whether or not a significant proportion is mediated by chandelier cell activation.

In summary, we show that the strength and origin of IPSCs correlates with their onset latency, and that short-latency IPSCs are mainly mediated by FS interneurons. We thus demonstrate the feasibility of LSPS in qualitatively distinguishing cell type specific inputs. Establishing cell type specific input maps and investigating factors contributing to the dynamics of neuronal activity (such as the fact that FS interneurons reach spike threshold significantly faster than pyramidal cells) are crucial to understanding neuronal circuits and the output of cortical networks.

\section{References}

Ali AB (2003) Involvement of post-synaptic kainate receptors during synaptic transmission between unitary connections in rat neocortex. Eur J Neurosci 17:2344-2350.

Ali AB, Rossier J, Staiger JF, Audinat E (2001) Kainate receptors regulate unitary IPSCs elicited in pyramidal cells by fast-spiking interneurons in the neocortex. J Neurosci 21:2992-2999.

Bacci A, Huguenard JR, Prince DA (2005) Modulation of neocortical interneurons: extrinsic influences and exercises in self-control. Trends Neurosci 28:602-610.

Bartos M, Vida I, Jonas P (2007) Synaptic mechanisms of synchronized gamma oscillations in inhibitory interneuron networks. Nat Rev Neurosci $8: 45-56$

Beierlein M, Gibson JR, Connors BW (2000) A network of electrically coupled interneurons drives synchronized inhibition in neocortex. Nat Neurosci 3:904-910.

Brill J, Huguenard JR (2008) Sequential changes in AMPA receptor targeting in the developing neocortical excitatory circuit. J Neurosci 28:13918-13928.

Campbell SL, Mathew SS, Hablitz JJ (2007) Pre- and postsynaptic effects of kainate on layer II/III pyramidal cells in rat neocortex. Neuropharmacology 53:37-47.

Clarke VR, Ballyk BA, Hoo KH, Mandelzys A, Pellizzari A, Bath CP, Thomas J, Sharpe EF, Davies CH, Ornstein PL, Schoepp DD, Kamboj RK, Collingridge GL, Lodge D, Bleakman D (1997) A hippocampal GluR5 kainate receptor regulating inhibitory synaptic transmission. Nature 389:599-603.

Dantzker JL, Callaway EM (2000) Laminar sources of synaptic input to cortical inhibitory interneurons and pyramidal neurons. Nat Neurosci 3:701-707.

Deleuze C, Huguenard JR (2006) Distinct electrical and chemical connectivity maps in the thalamic reticular nucleus: potential roles in synchronization and sensation. J Neurosci 26:8633-8645.

Freund TF, Katona I (2007) Perisomatic inhibition. Neuron 56:33-42.

Galarreta M, Hestrin S (2002) Electrical and chemical synapses among parvalbumin fast-spiking GABAergic interneurons in adult mouse neocortex. Proc Natl Acad Sci U S A 99:12438-12443.

Gibson JR, Beierlein M, Connors BW (1999) Two networks of electrically coupled inhibitory neurons in neocortex. Nature 402:75-79.

Jiang L, Xu J, Nedergaard M, Kang J (2001) A Kainate receptor increases the efficacy of GABAergic synapses. Neuron 30:503-513.

Jin X, Prince DA, Huguenard JR (2006) Enhanced excitatory synaptic connectivity in layer $\mathrm{V}$ pyramidal neurons of chronically injured epileptogenic neocortex in rats. J Neurosci 26:4891-4900.

Jin XT, Smith Y (2007) Activation of presynaptic kainate receptors suppresses gabaergic synaptic transmission in the rat globus pallidus. Neuroscience 149:338-349. 
Kang N, Jiang L, He W, Xu J, Nedergaard M, Kang J (2004) Presynaptic inactivation of action potentials and postsynaptic inhibition of GABA(A) currents contribute to KA-induced disinhibition in CA1 pyramidal neurons. J Neurophysiol 92:873-882.

Khirug S, Yamada J, Afzalov R, Voipio J, Khiroug L, Kaila K (2008) GABAergic depolarization of the axon initial segment in cortical principal neurons is caused by the Na-K-2Cl cotransporter NKCC1. J Neurosci 28:4635-4639.

Kumar SS, Jin X, Buckmaster PS, Huguenard JR (2007) Recurrent circuits in layer II of medial entorhinal cortex in a model of temporal lobe epilepsy. J Neurosci 27:1239-1246.

Marin-Padilla M (1972) Double origin of pericellular baskets of pyramidal cells of human motor cortex: a Golgi study. Brain Res 38:1-12.

Markram H, Toledo-Rodriguez M, Wang Y, Gupta A, Silberberg G, Wu CZ (2004) Interneurons of the neocortical inhibitory system. Nat Rev Neurosci 5:793-807.

Martina M, Jonas P (1997) Functional differences in Na+ channel gating between fast-spiking interneurones and principal neurones of rat hippocampus. J Physiol 505:593-603.

Martina M, Schultz JH, Ehmke H, Monyer H, Jonas P (1998) Functional and molecular differences between voltage-gated $\mathrm{K}+$ channels of fastspiking interneurons and pyramidal neurons of rat hippocampus. J Neurosci 18:8111-8125.

Mathew SS, Hablitz JJ (2008) Calcium release via activation of presynaptic IP3 receptors contributes to kainate-induced IPSC facilitation in rat neocortex. Neuropharmacology 55:106-116.

Molnár G, Oláh S, Komlósi G, Füle M, Szabadics J, Varga C, Barzó P, Tamás G (2008) Complex events initiated by individual spikes in the human cerebral cortex. PLoS Biol 6:e222.

More JC, Troop HM, Dolman NP, Jane DE (2003) Structural requirements for novel willardiine derivatives acting as AMPA and kainate receptor antagonists. Br J Pharmacol 138:1093-1100.

More JC, Nistico R, Dolman NP, Clarke VR, Alt AJ, Ogden AM, Buelens FP, Troop HM, Kelland EE, Pilato F, Bleakman D, Bortolotto ZA, Collingridge GL, Jane DE (2004) Characterisation of UBP296: a novel, potent and selective kainate receptor antagonist. Neuropharmacology 47:46-64.

Oliet SH, Piet R, Poulain DA (2001) Control of glutamate clearance and synaptic efficacy by glial coverage of neurons. Science 292:923-926.

Paternain AV, Morales M, Lerma J (1995) Selective antagonism of ampa receptors unmasks kainate receptor-mediated responses in hippocampal neurons. Neuron 14:185-189.

Ren M, Yoshimura Y, Takada N, Horibe S, Komatsu Y (2007) Specialized inhibitory synaptic actions between nearby neocortical pyramidal neurons. Science 316:758-761.
Schubert D, Staiger JF, Cho N, Kötter R, Zilles K, Luhmann HJ (2001) Layer-specific intracolumnar and transcolumnar functional connectivity of layer V pyramidal cells in rat barrel cortex. J Neurosci 21:3580-3592.

Schubert D, Kötter R, Zilles K, Luhmann HJ, Staiger JF (2003) Cell typespecific circuits of cortical layer IV spiny neurons. J Neurosci 23:2961-2970.

Shepherd GMG, Svoboda K (2005) Laminar and columnar organization of ascending excitatory projections to layer $2 / 3$ pyramidal neurons in rat barrel cortex. J Neurosci 25:5670-5679.

Somogyi P (1977) Specific axo-axonal interneuron in visual cortex of the rat. Brain Res 136:345-350.

Somogyi P, Kisvárday ZF, Martin KA, Whitteridge D (1983) Synaptic connections of morphologically identified and physiologically characterized large basket cells in the striate cortex of cat. Neuroscience 10:261-294.

Syková E (2004) Extrasynaptic volume transmission and diffusion parameters of the extracellular space. Neuroscience 129:861-876.

Szabadics J, Varga C, Molnár G, Oláh S, Barzó P, Tamás G (2006) Excitatory effect of GABAergic axo-axonic cells in cortical microcircuits. Science 311:233-235.

Szentágothai J, Arbib MA (1974) Conceptual models of neural organization. Neurosci Res Program Bull 12:305-510.

Tamás G, Buhl EH, Somogyi P (1997) Fast IPSPs elicited via multiple synaptic release sites by different types of GABAergic neurone in the cat visual cortex. J Physiol 500:715-738.

Thomson AM, West DC, Hahn J, Deuchars J (1996) Single axon IPSPs elicited in pyramidal cells by three classes of interneurones in slices of rat neocortex. J Physiol 496:81-102.

Wilding TJ, Huettner JE (1995) Differential antagonism of alphaamino-3-hydroxy-5-methyl-4-isoxazolepropionic acid-preferring and kainate-preferring receptors by 2,3-benzodiazepines. Mol Pharmacol 47:582-587.

Wonders CP, Anderson SA (2006) The origin and specification of cortical interneurons. Nat Rev Neurosci 7:687-696.

Xiang Z, Huguenard JR, Prince DA (2002) Synaptic inhibition of pyramidal cells evoked by different interneuronal subtypes in layer $\mathrm{V}$ of rat visual cortex. J Neurophysiol 88:740-750.

$\mathrm{Xu}$ X, Callaway EM (2009) Laminar specificity of functional input to distinct types of inhibitory cortical neurons. J Neurosci 29:70-85.

Yoshimura Y, Callaway EM (2005) Fine-scale specificity of cortical networks depends on inhibitory cell type and connectivity. Nat Neurosci 8:1552-1559.

Yuste R (2005) Origin and classification of neocortical interneurons. Neuron 48:524-527. 